\title{
Modelling Digital Knowledge Transfer: Nurse Supervisors Transforming Learning at Point of Care to Advance Nursing Practice
}

\author{
Carey Mather ${ }^{1, *}$ and Elizabeth Cummings ${ }^{2}$ \\ 1 School of Health Sciences, Faculty of Health, University of Tasmania, Launceston Campus, \\ 7250 Tasmania, Australia \\ 2 School of Health Sciences, Faculty of Health, University of Tasmania, Hobart Campus, 7000 Tasmania, \\ Australia; Elizabeth.Cummings@utas.edu.au \\ * Correspondence: Carey.Mather@utas.edu.au; Tel.: +61-363-243-149
}

Academic Editor: Antony Bryant

Received: 15 March 2017; Accepted: 16 May 2017; Published: 18 May 2017

\begin{abstract}
Limited adoption of mobile technology for informal learning and continuing professional development within Australian healthcare environments has been explained primarily as an issue of insufficient digital and ehealth literacy of healthcare professionals. This study explores nurse supervisors' use of mobile technology for informal learning and continuing professional development both for their own professional practice, and in their role in modelling digital knowledge transfer, by facilitating the learning and teaching of nursing students in the workplace. A convenience sample of 27 nurse supervisors involved with guiding and supporting undergraduate nurses participated in one of six focus groups held in two states of Australia. Expanding knowledge emerged as the key theme of importance to this group of clinicians. Although nurse supervisors regularly browsed Internet sources for learning and teaching purposes, a mixed understanding of the mobile learning activities that could be included as informal learning or part of formal continuing professional development was detected. Participants need educational preparation and access to mobile learning opportunities to improve and maintain their digital and ehealth literacy to appropriately model digital professionalism with students. Implementation of mobile learning at point of care to enable digital knowledge transfer, augment informal learning for students and patients, and support continuing professional development opportunities is necessary. Embedding digital and ehealth literacy within nursing curricula will promote mobile learning as a legitimate nursing function and advance nursing practice.
\end{abstract}

Keywords: access; continuing professional development; digital literacy; digital knowledge; digital professionalism; ehealth literacy; informal learning; mobile learning; nursing

\section{Introduction}

Implementation of mobile learning for informal learning and continuing professional development within healthcare settings has been slow. Previous research indicates there are systemic, organisational, and individual impediments that have contributed to this lack of realisation of the potential to transfer digital knowledge and transform learning at point of care [1]. The focus of this study was to explore nurse supervisor use of mobile technology for informal learning and continuing professional development (CPD) both for their own professional practice and in their role of facilitating student nurses' learning in practice. Nurse supervisors shared their opinions and experiences of how they managed the access and retrieval of information for informal learning of students and CPD using mobile or portable devices.

Royle and Blythe [2] discussed the use of information systems by nurses to remain current in their field. They reported that nurses show differences in awareness of research and availability 
of information resources and acknowledged there was a need for collaboration among healthcare organisations and academic institutions, leading to a global healthcare community. They predicted in the future there would be a need for "improved organisational and environmental support for nurses to work with increasingly sophisticated information systems" [2]. The changes outlined by Royle and Blythe [2] have emerged in nursing practice, and it is now imperative for nurses to be both digitally and ehealth literate within healthcare environments. Similarly, it is essential for nurse supervisors to be digital and ehealth literate to promote digital knowledge transfer, so they are able to model digital professionalism with students in the workplace [3].

The Australian National Statement on Health Literacy [4] defines health literacy within an individual or environment context. Individual health literacy pertains to the capacity of a person to access and utilise information to formulate healthcare decisions and actions. Health literacy environment refers to elements that comprise the health system including the infrastructure, policies and resources that influence how people interact with, and apply health information and services [4]. The addition of the dimension of digital or electronic health literacy, known as ehealth literacy, provides further complexity to this concept. As digital technology has evolved, the need for supporting digital and ehealth literacy of the health profession workforce and with patients to enable digital knowledge transfer has also increased.

Digital professionalism has emerged as a component of professional identity formation of health professionals, as they need to behave appropriately when using technology within healthcare environments. An element of this new literacy is the opportunity to undertake informal learning and CPD at point of care, in real time in the workplace. Understanding the factors that affect the capacity of nurses to transform learning using mobile technology at point of care needs to be considered. Harnessing digital literacy and embedding ehealth literacy into nursing courses, and promoting modelling of digital professionalism to promote digital knowledge transfer, will support the acceptance and use of mobile learning for informal learning as a legitimate nursing function in healthcare environments [5]. Transformation of learning and teaching to enable transfer of digital knowledge, through the inclusion of mobile learning into everyday nursing practice, will ensure nurses have options to advance nursing practice by accessing current evidence-based information as required [6,7].

Acknowledgement of a changing world where mobile technology is ubiquitous in the environment enables opportunity for the nursing profession to be innovative and remain a contemporary discipline. The Nursing and Midwifery Board of Australia provides impetus for enabling nurses to harness mobile technology for capturing informal learning in the workplace as part of CPD required for annual registration as a nurse [8]. The Australian Nursing and Midwifery Accreditation Council mandates that all accredited nursing programs are required to include nursing informatics $[9,10]$. These standards further support using digital strategies for CPD and the development of digital professionalism by stating that health technology and informatics need to be embedded at a technical, contextual, and emancipatory level [10]. The impact of mandatory CPD for nurses is being realised, and recognition of flexibility in learning opportunities to include new strategies is necessary to consider different situations and learning styles [11].

Nurses undertake CPD using a range of educational strategies including traditional methods such as face-to-face attendance at workshops and conferences or completion of online learning packages. The proliferation of digital media choices has expanded to include proprietary software including applications known as apps, and portfolios to enable nurses to document and store evidence of CPD. Commercial apps provide prompts to ensure users meet their own goals for CPD, plus tracking and reminder systems including letting users know how much CPD they have undertaken. Professional bodies, societies, and non-profit organisations provide free or for-fee CPD options. These portals also support documentation of other CPD undertaken external to the platform [12-15]. Professional [16,17] and healthcare organisations [18,19] provide contemporary information on local intranets that support nurses completing their annual CPD requirements. 
Investigation of the information-seeking behaviour of nurses reveals that, at point of care, nurses pursue information about post-treatment follow-up or recovery. They also access and retrieve information about health assessments, problems, disease, treatment of patients, and other allied health disciplines [20]. This means nurses can now access information at point of care in real time, rather than needing to go to a library, a nurses' station, an office, or a university campus or to return home before being able to search for the information required. However, preparation and training within nursing courses, and easy access to and availability of the Internet in the workplace is required to enable convenient, timely access to information that can improve health outcomes of patients and augment nursing practice by promoting transfer of digital knowledge in the workplace [20,21].

Access to web-based information or intranets can assist nurse supervisors instructing student nurses with decision-making. Nurse supervisors need to model access and use of high-quality reliable Internet sources. Factors that influence trust judgements of health information relate to individual and website factors.

A previous study [22], which explored the ways in which nurses discern credible information, found they used tacit, process, and propositional knowledge, as well as intuition. Nurses employed quasi-rational cognition and analysis to appraise evidence to judge webpage quality. They also used cues of accuracy, relevance, completeness and amount of data provided before deciding whether the information was credible or reliable.

Furthermore, socio-demographic, personality, health status, and level of health literacy impact on trust judgements of individuals. Prior experience, perceived reputation, risk, and familiarity also swayed determination of information [23]. Lack of time increased the risk of nurses utilising lower quality Internet sites for information [22,24]. However, Yang and colleagues [25] found that, in simulated conditions, nurses reason adaptively in time-limited situations and make judgements without compromising accuracy of outcomes [25]. Enabling easy access to web-based health information can reduce time pressure, support decision-making, and maintain judgement accuracy at point of care [25].

The preparation of students to retrieve and assess Internet health information and discern credible Internet sites needs to be overtly included in the curriculum, the classroom, and practised prior to going into the workplace [26,27]. Perhaps more importantly, nurse supervisors require preparation to facilitate proficiency in digital literacy and ehealth literacy to ensure there is consistency in approach to modelling access and using web-based or Internet-enabled information for digital knowledge transfer to students in healthcare environments [28,29]. Preparation of nurse supervisors to be competent and confident in using mobile technology in the workplace for learning and teaching can augment learning opportunities and influence student satisfaction of their healthcare experiences [30].

Since the advent of easy, convenient access to information through the Internet, patients or consumers have become participants in their own care. A new aspect of the role of nurse supervisors is to model patient inclusion and education, and assist with promotion of digital and ehealth literacy. Nurse supervisor proficiency in digital and ehealth literacy and modelling digital knowledge transfer as a component of digital professionalism assists with facilitating rapport development and mutuality of understanding between students and patients that can create positive learning environments [3].

Change in nursing practice now includes knowledge management, and digital and ehealth literacy is imperative for nurse supervisors. The opportunity to transform learning at point of care to advance nursing practice using mobile learning is here. Understanding how to model digital professionalism for informal learning and CPD in the workplace will require engagement with the process of change, to enable the safe and appropriate use of mobile learning in the workplace. Entrustment to use credible web-based resources informal learning and CPD at point of care is also necessary, to ensure appropriate modelling with students and to encourage the formation of a positive professional identity during healthcare experiences [5]. 


\section{Materials and Methods}

Recruitment for the study was through convenience sampling of nurse supervisors employed by one Australian university. Invitations to participate were emailed to all nurse supervisors employed in a range of healthcare settings who were involved with guiding and supporting undergraduate students from the University in two Australian states. Twenty-seven nurse supervisors elected to be participants in one of six focus groups. The focus groups were conducted between July and November 2014. The focus groups included between three and seven nurse supervisors, with approximately half of the participants from each State ( 13 from New South Wales and 14 from Tasmania). Focus group sessions were held on three university campuses (one in New South Wales and two in Tasmania) and were approximately 1 hour in duration, audio-recorded, and transcribed verbatim.

This exploratory study aimed to investigate nurse supervisor's use of mobile technology for informal learning and CPD, both for their own professional practice and in their role of facilitating learning and teaching of nursing students in the workplace. Therefore, the focus group sessions opened with specific questions about mobile technology and its use by the nurse supervisors. This approach then prompted discussion to elicit information about mobile learning strategies used by nurse supervisors in the workplace. Free discussion ensued from the initial questions and focussed on strategies they used for CPD with additional prompts to elicit information about how they used mobile learning. Within this exploratory framework, participants discussed their current CPD practices.

Thematic analysis was undertaken independently by two researchers followed by discussion and cross-checking of themes and sub-themes to reach consensus. Ethics approval for this study was gained through the Tasmanian Human Research Ethics Committee, approval number H0013729.

\section{Results}

Participants were nurse supervisors who guided and supported undergraduate nurses from one university within a range of healthcare settings, during work-integrated learning, as part of their undergraduate degree. The nurses who participated in these focus groups had previously supervised nursing students. More than half the participants had supervised students for more than five years. Of the Tasmanian cohort, approximately half of the participants practiced in community settings and half were from tertiary healthcare facilities, whereas participants from New South Wales, Australia, were employed as nurse supervisors in both settings. Other participant demographic characteristics were not recorded.

Thematic analysis of the focus groups indicated nurse supervisors constantly associated learning and teaching with access and use of mobile technology for digital knowledge transfer at point of care. Through this linkage, the theme of Expanding Knowledge emerged as key. Using mobile technology to expand knowledge and support learning opportunities was a priority expressed in all focus groups. Overt enthusiasm was displayed by nurse supervisors for the potential of using Internetand web-based resources to access and retrieve information, construct knowledge, verify information, and share learning in real time with students or patients while in the workplace.

Participants also indicated informal learning and CPD were enabled by using mobile technology at point of care. Discussions regarding how to utilise this new andragogy to assist with meeting their annual requirements for CPD as evidence of learning ensued. Lack of confidence in using mobile technology or lack of digital and ehealth literacy was of concern to this group of nurses. Access to mobile learning varied due to organisation policy and data, and local rules at point of care was also a focus of discussion. They were keen to remain up-to-date in their role by modelling appropriate behaviour when accessing mobile technology for learning purposes.

Participants were aware of the potential overload of information available to learners and were keen to access relevant information at their convenience as required. One participant (Focus Group 1) acknowledged the following: 
"I think we need to continue. The world is changing. The world is becoming more and more mobile. We as a profession need to adapt and keep up with that as well. We need to be constantly looking up because we don't know everything. We can't possibly know everything. We have to continue to research. I'm very pro having the mobile technology".

The three sub-themes of evidence of learning, digital literacy, and access are integral for learning and teaching at point of care. These sub-themes support the emergent key theme of expanding knowledge. Expanding knowledge was important to nurse supervisors as being able to access informal learning in real time or undertake CPD using mobile learning opportunities were acknowledged to be of value. Participants understood digital and ehealth literacy was fundamental to modelling digital professionalism and enabling digital knowledge transfer with students. They also realised lack of access to mobile technology at point of care contributed to hindering ingress to this learning and teaching strategy. Each of the sub-themes of evidence of learning, digital literacy, and access is explained in detail below.

\subsection{Evidence of Learning}

Evidence of learning includes informal learning moments and CPD activities that promote nurses, students, and patients to gather and interpret information to enable the construction of knowledge. Utilisation of these situated learning opportunities may or may not be documented to show evidence of learning. Intangible evidence of learning are the behavioural changes that result from linking theory with practice, which enables comprehension and development of meaning as the learner understands and creates new knowledge. Formal documented evidence of learning by nurses is expected through the identification of learning needs, an action plan, and reflection, are also required annually as part of maintaining registration as a nurse.

Within the sub-theme evidence of learning, participants indicated that the drive for meeting their formal CPD requirements as evidence of learning and maintaining contemporary in their field was constant. Nurse supervisors were keen to participate in easily accessible CPD topics that were identified as part of their annual learning plan. They initially acknowledged CPD "they're all online" (participant, Focus Group 6), but also reported undertaking other types of in-service training that included face-to-face sessions and conference attendance.

Participants indicated mandatory CPD was the focus of much of their documented online learning with one participant stating:

"all our mandatory competencies now are pretty much online" (participant, Focus Group 4).

Expanding upon the range of digital mandatory CPD requirements, the participants offered a wide range of topics they had completed as part of their formal CPD. Participants reported the types of web-based resources they accessed. One nurse supervisor (Focus Group 4) stated:

"There's hand hygiene, there's manual handling. There's basic life support so that would be two,

3.5 hours there. There's smoking cessation, there's another half an hour, there's four".

At some organisations participants could undertake CPD using the staff intranet. Provision of this digital platform enabled them to complete their annual mandatory training online. Participants mentioned they accessed or purchased online CPD packages offered by professional bodies or commercial organisations. Participants also disclosed undertaking a range of free formal CPD opportunities offered by societies or organisations. This type of CPD enabled participants to gain evidence of their learning. One nurse supervisor (Focus Group 4) divulged:

"So you go in there, you login, you can look up the article, read the article they are usually only one or two pages ... then you go back in and click on another link and there's a quiz that pops up and gives half an hour or an hour's worth of CPD points ... its free". 
Flexibility of undertaking online informal learning or CPD was acknowledged. One participant (Focus Group 2) noted:

"I guess it's a convenience, you don't have to take time out to go to the venue, if you can find something equally as interesting online".

Nurse supervisors had considered informal learning opportunities could be included as CPD as evidence of learning and indicated they were satisfied to "learn as you go" (participant, Focus Group 2). Nurse supervisors indicated they were aware that, for learning to be included as CPD, it needed to be recognised as new knowledge:

"if there's something new in in it you can count it, if it's something you've learnt" (participant, Focus Group 6).

Regarding the documenting of informal learning, nurse supervisors reported: "I thought we had to" (participant, Focus Group 5), whilst another participant mentioned they had "not even considered it [informal learning] to be honest until you said that" (participant, Focus Group 3) when discussing using Internet- or web-based informal learning for inclusion as CPD. Those participants who understood informal learning could contribute to formal CPD as evidence of learning expressed statements such as the following:

"It's meant to be about a point an hour of learning, so we'd smash it" (participant, Focus Group 4) and: "I think that's why I haven't bothered to keep up with writing everything up because that's what I would do if I got audited" (participant, Focus Group 3).

Nurse supervisors could foresee that students could augment learning by having access to informal learning opportunities and sharing their learning via digital knowledge transfer at point of care:

"I think it's a useful tool to have at their disposal and I think they are lucky to be able to do that. It's at their fingertips so they should be able to get answers very quickly, which I think is great for them. I know they do a lot of group chats and things... if they could put up something on that group chat at the time of how they're feeling, something they've discovered. I think being able to communicate between each other is a really good thing" (participant, Focus Group 2).

Evidence of learning was important to nurse supervisors. They indicated facilitating the construction of knowledge was integral to their role as nurse supervisors. However, they also recognised learning in real time could be of benefit to other nurses, students, and patients. Although completing formal CPD was a focus, verification of learning was not limited to documented evidence required for maintenance of registration. This group of nurses indicated that informal learning and facilitating learning using mobile technology also supported opportunities to construct new knowledge that was evident through less tangible means, such as behaving in a digital professional manner.

Evidence of learning is important in demonstrating expanding knowledge at point of care using mobile technology. This sub-theme provides a means by which nurse supervisors can systematically demonstrate and record their learning. This sub-theme directly relates to each of the other sub-themes, as for evidence of learning to be achieved the nurse supervisors must also demonstrate digital literacy and have appropriate access.

\subsection{Digital Literacy}

Nurse supervisors identified that expanding knowledge was enhanced by developing their own digital and ehealth literacy. The sub-theme of digital literacy encompassed competency or capability of individuals in using digital technology for learning and teaching. Nurse supervisors also indicated that ehealth literacy includes knowing how to find clinical or health-related information using mobile 
technology formed a component of digital literacy. Both of these elements contribute to enabling expanding knowledge.

Participants reported accessing most of their learning using digital platforms. They were concerned about their level of digital and ehealth literacy. From focus group discussions, it was evident there was a range of levels in confidence and skills in accessing and retrieving information from the Internet using mobile technology. Participants were also aware as part of their role to enable digital knowledge transfer they needed to be digital and ehealth literate. Nurse supervisors indicated they were expected to model appropriate competency and appropriate behaviour in using, and teaching others how to use, mobile technology for access and retrieving credible information from the Internet.

Nurse supervisors recognised their digital literacy proficiency was inadequate at times. One participant noted:

"When I first came out of uni they didn't believe I was computer illiterate. They thought I was joking" (participant, Focus Group 5).

Nurse supervisors also realised that continued use and exposure to digital technology maintained proficiency in digital literacy:

"No I don't do it enough. It's one of those skills that if you don't use it all the time you lose it... unless I'm playing around it (skills) drop off dramatically" (participant, Focus Group 3).

To gain knowledge or maintain digital literacy, participants also mentioned seeking assistance from family members when they had technology issues.

"I mean there are some things I am not confident with, but there's usually a way around it and you can ask one of your friends or something, someone always knows" (participant, Focus Group 1).

Digital literacy impacted on participants' capacity to gain evidence of learning. Nurse supervisors' level of knowledge and skills in relation to the digital world was of concern to them. They realised there was inconsistency in their knowledge, and had variable access to opportunities to improve their level of proficiency in digital and ehealth literacy.

Participants recognised they could facilitate and augment learning opportunities if they were confident and competent in guiding students or patients in using mobile technology for digital knowledge transfer. Nurse supervisors were keen to capitalise on informal learning opportunities with students and patients at point of care. They provided examples of how using mobile learning in real time could be of benefit to learners. One participant (Focus group 4) stated:

"Something comes up. You think, Oh that's really good. I have something here. Now that we're talking about it or doing it, look at this. Then it'll make more sense and things like that. Then you can just do it there, especially as a facilitator, so it's immediate."

Nurse supervisors were aware that some patients were digitally literate and believed that there was an onus on them as healthcare providers to guide these patients in finding credible health information:

"I mean the older patients have their mobiles and they're on them all day. They've got their apps and stuff like that" (participant, Focus Group 1).

Participants also indicated that the promotion of digital and ehealth literacy of patients could be undertaken by nurses if they were digitally literate. One participant stated:

"For a patient I think it's different if they've said can you tell me and you might say let's look it up together. I think that's different than if it's just your personal learning needs" (participant, Focus Group 6). 
Nurse supervisors also articulated concerns of the potential for inappropriate behaviour of "staring at screens" and "not being present" when using mobile or portable devices at point of care. Nurse supervisors were keen to be digital and ehealth literate and able to model digital professionalism with students. One participant revealed (Focus Group 3):

"Even just not ignore the patient and have everybody staring at a screen talking about them rather than to them".

Participants were keen to acknowledge patients during learning interactions. They realised that using digital technology at point of care provided opportunity to include patients in their own care and promote patient-centred care. Being digitally literate facilitated learning of patients. One participant (Focus Group 2) indicated:

"So whenever I look at these things I've always attempted to integrate interpersonal contact with the patient as well because I'll be able to see that they're sitting there feeling like, oh well, may as not be here. So I think it's something that needs to be taught that these things can affect and to try and bring it back to some patient-centred interaction".

Participants announced they would like to be more educationally prepared to be digitally literate to enable them to model digital professionalism with students. Nurse supervisors from different focus groups commented:

"If you're not computer savvy ... " "Work has never given me time to learn computers, IT stuff" (Focus Group 6),

"we're struggling with it because we haven't been educated" (participant, Focus Group 4), and

"we need training and development to be able to provide us with something like that" (participant, Focus Group 6).

Participants suggested not only did they need educational preparation in using mobile or portable devices, they also required knowledge about accessing credible websites. Participants indicated that, through the educational preparation process, they could learn about how to use digital technology and what resources were available to seek, retrieve, and transfer knowledge to students or patients:

"as part of your learning you would be using reputable sites as well" (participant, Focus Group 3).

Participants indicated this dual educational strategy would support development of nurse supervisor proficiency in digital and in ehealth literacy. Participants also noted the wide range of resources available on the Internet and discussed the lack of consistency of resources. Nurse supervisors developed their own solutions to the myriad of digital educational resources available; for example,

"the hospital if we went electronic that they could probably give us an update of which sites are the ones to be using" (participant, Focus Group 4)

and "the top 10 sites" (participant, Focus Group 3).

Other participants were aware they needed to guide students in developing digital professionalism, including ensuring students were aware of credible sources of health information. This function of supervision relied on them having sufficient digital literacy to be able to guide students.

"I guess you just want to make sure they're going to good sites, legitimate sites" (participant, Focus Group 3).

Nurse supervisors were keen to ensure students did access credible sources of information. A participant (Focus Group 2) observed:

"The problem is who has the time to go on the sites to see what they're looking up". 
To model digital professionalism to students and patients, nurse supervisors revealed they vetted Internet resources such as YouTube clips for suitability. One participant stated, due to the lack of suitable resources, "I make up my own" (participant, Focus Group 2).

Consistency of resources was mentioned, with one nurse supervisor suggesting the following:

"I think it would be lovely if we had a suite - not to re-invent the wheel, but if there were credible ones out there, so you could get a suite together of stuff so everyone was consistent in what they were showing students" (participant, Focus Group 2).

Participants indicated they wanted the best educational outcomes for their students and being digital and ehealth literate enabled them to model digital professionalism confidently within healthcare settings.

Nurse supervisors were aware of their role in supporting other nurses as well as students. They understood part of their function as teachers, was to promote and support digital and ehealth literacy of their peers. They also realised there was a mutuality of understanding that could develop, as students could impart their digital knowledge to preceptors and patients, while increasing their health knowledge through participating in the care of patients at point of care

"I can see there would be problems with how preceptors feel about it and how they assist the students to use it because I don't think they would be 'au fait' with and up-to-date with how to use it as well. You're teaching the preceptor. It's not so bad because then you've got the preceptor giving information and then the student providing information as well" (participant, Focus Group 5).

Analysis indicates that digital literacy is critical in contributing to expanding knowledge. Being able to utilise digital platforms proficiently is fundamental to their role. The ability to use digital technology at point of care for learning and teaching purposes was also important in contemporary nursing practice for enabling digital knowledge transfer and expanding knowledge.

\subsection{Access}

Access in this context refers to nurses, nurse supervisors, students, or patients having access to the Internet via mobile technology to seek or retrieve health information at point of care. The sub-theme of access was recognised by participants as being integral to enabling digital knowledge transfer at point of care.

Participants indicated the ability to undertake informal learning or CPD using mobile or portable devices was dependent on ingress to the Internet or local intranets at point of care. Nurse supervisors were conversant with options available to access learning and teaching resources for informal learning and CPD. They had a strong understanding of the limitations of accessing information while in the workplace. Participants reporting mobile applications or apps to support learning using organisation intranets were not supported, and retrieving information in the workplace was often possible only by accessing a desktop computer:

"Yeah I think the only frustrating thing is it's time-consuming ... and getting access to computers" (participant, Focus Group 6).

Use of organisation provided wireless Internet services is restricted in some Australian healthcare settings. Nurse supervisors grappled with using sanctioned intranet resources, which may be limited. One participant stated:

"some stuff the students want to know about is not on the intranet. It's on the Internet. So you can't Google it because it won't allow you" (participant, Focus Group 1).

They indicated that the majority of access to the Internet for informal learning at the workplace was undertaken using their personal mobile devices, at their own cost: For example, 
"well you end up using your own (data), yeah. Then it comes down to data usage. You might only have one 'gig' of data on your phone and then you're limited" (participant, Focus Group 1).

Participants suggested there was a lack of consistency in access to mobile learning, that was confusing in the workplace as expectations of staff and students were incongruent. They indicated that, in some healthcare settings, they are bound by organisational policy that precluded the use of mobile technology at point of care. However, it could be argued that the role of learning and teaching is different to being part of a workplace where each nurse has a patient allocation or workload. These nurse supervisors suggested they should be able to access mobile learning at point of care because their main focus is learning and teaching rather than patient care. This participant revealed:

"I think a lot of those policies and procedures are aimed at people who are there in the clinical workforce, so the concern is you're doing personal stuff on your phone, rather than looking after patients. Whereas we don't have a patient load, our responsibility is towards the student, so using our own personal device to get information to facilitate the learning of the student, I think that's a different sort of situation altogether" (Focus Group 5).

Access issues also related to equipment. Provision of appropriate mobile technology, weight of devices and theft were also issues raised by participants. Appropriateness of mobile devices for learning and teaching were also discussed. One nurse supervisor stated:

"The mini (Ipod mini) would be useful because of the weight that we do carry ... trying to show to more than three people, they're not big enough" (Focus Group 2).

Access is integral to digital knowledge transfer as part of expanding knowledge. No access to mobile learning at point of care renders digital or ehealth literacy irrelevant. Without digital access, nurse supervisors are unable to use this new andragogy to guide and support students undertaking work-integrated learning, nor can they promote patient engagement with their own care. Informal learning and CPD is an implicit function of being a nurse. Being able to utilise mobile technology at point of care supports digital and ehealth literacy, promotes evidence of learning, and provides opportunities for expanding knowledge.

\section{Discussion}

Nurse supervisors understand learning and teaching strategies are changing, evidenced by their own disclosure of types of formal CPD undertaken to meet their annual requirements for registration. Evidently, some were more conversant with activities that could be included as CPD, while others continued to utilise more traditional methods such as face-to-face workshops or conferences. However, most participants accessed online learning packages to complete their mandatory organisational CPD requirements. Ross and colleagues [11] previously indicated that mandatory CPD for Australian nurses would impact their practice, and this study demonstrates that nurses utilise the range of resources available to them to maintain their registration.

Coupled with the continued growth of mobile technology in personal and professional life [31] the requirement for mandatory $\mathrm{CPD}$ has created pressure within organisations that informal learning using a mobile or portable device be extended and accepted as a legitimate method of learning within the workplace [32].

This study demonstrates the need for further preparation to ensure nurse supervisors are digitally literate and proficient in using mobile technology to facilitate mobile learning activities. Preparation includes becoming confident and competent in using mobile or portable devices and being able to discern appropriate Internet resources suitable for learning and teaching purposes. Nurse supervisors in this study indicated they would like to become more digital and ehealth literate, admitting at times that they struggle with using the Internet, especially as no educational preparation in using digital technology for transfer of digital knowledge is provided during work hours. 
Patients and the next generation of nurses are beginning to expect to use mobile technology at point of care [6], but to achieve this nurse supervisors need the ability to guide students to develop digital professionalism by modelling appropriate behaviour. Currently, they do not have the time or inclination to constantly check what information students access, suggesting that appropriate utilisation of mobile technology for informal learning needs to start early in the nursing curriculum [26].

Congruency of instruction on and off campus regarding mobile learning will promote proficiency in digital and ehealth literacy of students that can be translated to digital knowledge for assisting patients at point of care. Additionally, development of digital professionalism as part of professional identity formation will foster entrustability of the next generation of nurses, which will assist with the maintenance of a high reputation of nurses as a professional group [33].

Nurse supervisors are motivated to complete their annual CPD requirements and use 'pull' learning to access what they need as they need it, to achieve their aims [34]. Mobile learning in the workplace has the capacity to transform learning, through the transfer of digital knowledge at point of care, as nurses can access and retrieve information in real time without leaving the patient. Motivation to obtain information is typical of informal learning where information is required to enable rapid adaption or use. This behaviour reported by Yang and colleagues [25] demonstrated that nurses reason adaptively.

Empowerment of learners is possible when access to mobile learning is available as they access and retrieve information and construct knowledge in real time [3]. Furthermore, access to Internet-enabled learning within healthcare environments promotes patient-centred care and student-focussed learning. However, nurse supervisors in this study reported a lack of consistency in accessing the Internet or capacity to use mobile or portable devices proficiently in the workplace, hindering support of their own and student learning at point of care. Nurse supervisors indicated they wanted change to enable access to information for enabling transfer of digital knowledge to facilitate patient-centred care and harness student-focussed learning.

Study findings indicate that nurse supervisors are engaged in high quality learning outcomes for their students. These nurses found, vetted, and developed their own online resources to assist with learning and teaching of students in the workplace. Additionally, they are prepared to use their own devices, at their own cost, to ensure students have access to timely information to advance their nursing practice. Previous studies have reported that, although the use of mobile learning is generally ad hoc within healthcare settings, nurse supervisors are aware of the potential of this as a strategy to augment traditional learning and teaching methods $[1,3]$.

Change is slow and there is impetus for nurse leaders and organisations to progress support for learning in the workplace to facilitate learner-focussed education in contemporary healthcare environments. Acknowledgement by nurses for consistency in accessing and using Internet resources will enable dialogue about developing standards and codes of conduct for guiding mobile learning access and use in healthcare environments.

This study supports the notion that nurses and students would benefit from guidance in using mobile technology within healthcare settings. A clear direction about access and use of digital technology to promote digital and ehealth literacy would support the development of confidence and competence of nurses, facilitate development of digital professionalism of students, and enable guidance of digital and ehealth literacy of patients at point of care. Implementation of mobile learning has the capacity to model digital knowledge transfer, transform learning, and advance nursing practice in the workplace. Prioritisation of a plan for action to enable mobile learning for expanding knowledge using mobile technology within healthcare settings will enable this new andragogy for learning, promote completion of $\mathrm{CPD}$, and enable best clinical practice for students and supervisors. 


\section{Conclusions}

Mobile technology use in everyday life continues to increase, creating pressure for nurse supervisors to be adequately prepared and proficient in using mobile technology in the workplace. Nurses in healthcare settings need to understand informal learning at point of care can be included as a form of CPD. They need to be supported, encouraged, and prepared to become proficient in using mobile technology, so they can model the transfer of digital knowledge and appropriate behaviour with the next generation of nurses. Nurse supervisors must be proficient in modelling digital professionalism when accessing mobile technology for learning and teaching in the workplace. Preparation includes being able to access, retrieve, and discern credible information from the Internet in real time. Modelling appropriate behaviour includes being confident and competent in using mobile technology to promote the digital and ehealth literacy of patients.

This study found expanding knowledge was hindered by a lack of access to mobile technology that needs to be ameliorated, to enable mobile learning to become an adjunct to traditional learning and teaching methods at point of care. Preparation of the environment for students is vital for implementation of this innovation. Nurse supervisors acknowledged their role in guiding and enabling students to become work-ready by being prepared and proficient in accessing and retrieving information in real time, and decision-making about when it is safe and appropriate to do so. This includes ensuring students and nurses have digital and ehealth literacy commensurate with being able to undertake online CPD and have ehealth literacy levels to participate in informal learning at point of care. Prioritisation of issues for progression of being able to transfer digital knowledge using mobile technology to enable expanding knowledge within healthcare settings, will require nurse leaders to effect change in organisational policies, to recognise mobile learning as a legitimate nursing function.

Author Contributions: Carey Mather and Elizabeth Cummings conceived and designed the research; Carey Mather conducted the focus groups; Carey Mather and Elizabeth Cummings analysed the data; Carey Mather and Elizabeth Cummings wrote the paper.

Conflicts of Interest: The founding sponsors had no role in the design of the study; in the collection, analyses, or interpretation of data; or in the writing of the manuscript. Both authors are editors of the special issue, but this paper was subject to blind peer review and they had no influence in the decision to publish the article.

\section{References}

1. Mather, C.A.; Cummings, E. Unveiling the mobile learning paradox. Stud. Health Technol. Inform. 2015, 218, 126-131.

2. Royle, J.; Blythe, J. Promoting research utilisation in nursing: The role of the individual, organisation, and environment. Evid. Based Nurs. 1998, 1, 71-72.

3. Mather, C.A.; Cummings, E. Empowering learners: Using a triad model to promote ehealth literacy and transform learning at point of care. Knowl. Manag. E-Learn. Int. J. 2015, 7, 629-645.

4. ACSQHC (Australian Commission on Safety and Quality in Health Care). National Statement on Health Literacy: Taking Action to Improve Safety and Quality. Available online: https:/ / www.safetyandquality.gov. au/our-work/patient-and-consumer-centred-care/health-literacy/ (accessed on 25 February 2017).

5. Mather, C.A.; Cummings, E. Issues for deployment of mobile learning by nurses in Australian healthcare settings. Stud. Health Technol. Inform. 2016, 225, 277-281.

6. Risling, T. Educating the nurses of 2025: Technology trends of the next decade. Nurse Educ. Pract. 2017, 22, 89-92.

7. Mackay, B.; Anderson, J.; Harding, T. Mobile technology in clinical teaching. Nurse Educ. Pract. 2017, 22, 1-6.

8. NMBA (Nursing and Midwifery Board of Australia). Registration Standard: Continuing Professional Development. Available online: http:/ /www.nursingmidwiferyboard.gov.au/News/2016-02-01-revisedstandards.aspx (accessed on 2 March 2017). 
9. ANMAC (Australian Nursing and Midwifery Accreditation Council). Australian Nursing and Midwifery Accreditation Council Registered Nurse Accreditation Standards. Available online: http://www. anmac.org.au/sites/default/files/documents/ANMAC_RN_Accreditation_Standards_2012.pdf (accessed on 2 March 2017).

10. ANMAC (Australian Nursing and Midwifery Accreditation Council). ANMAC Health Informatics and Health Technology_An Explanatory Note 2014. Available online: http://www.anmac.org.au/sites/ default/files/documents/20150130_Health_Informatics_Technology_Explanatory_Note.pdf (accessed on 2 March 2017).

11. Ross, K.; Barr, J.; Stevens, J. Mandatory continuing professional development requirements: What does this mean for australian nurses. BMC Nurs. 2013, 12,1.

12. AUSMED. CPD Organiser. Available online: https://www.ausmed.com.au/cpd (accessed on 2 March 2017).

13. Chandler, T.J. CPD Nursing Log. Available online: https://itunes.apple.com/vn/app/cpd-nursing-log/ id640087130?1=vi\&mt=8 (accessed on 2 March 2017).

14. iFolio. Ifolio. Available online: https:/ / www.ifolio.com.au/ (accessed on 2 March 2017).

15. HETI (Health Education and Training Institute). Continuous Professional Development (CPD) in Heti Online. Available online: http:/ / www.heti.nsw.gov.au/HETIOnline/cpd (accessed on 2 March 2017).

16. ACN (Australian College of Nursing). Continuing Professional Development. Australian College of Nursing. Available online: https:/ /www.acn.edu.au/cpd (accessed on 2 March 2017).

17. ANMF (Australian Nursing and Midwifery Federation). Continuing Professional Education. Available online: http:/ / anmf.org.au/cpe (accessed on 2 March 2017).

18. Calvary Healthcare. Employee Resources. Available online: https://www.calvarycare.org.au/careers/ employee-resources/ (accessed on 2 March 2017).

19. North Coast Primary Health Network. Continuing Professional Development. Available online: http:/ /ncphn.org.au/continuing-professional-development/ (accessed on 2 March 2017).

20. Singh, S.; Mahapatra, R. Electronic information seeking behaviour among nursing students and teachers: A review. IJHSR 2016, 6, 470-485.

21. Maloney, S.; Chamberlain, M.; Morrison, S.; Kotsanas, G.; Keating, J.L.; Ilic, D. Health professional learner attitudes and use of digital learning resources. J. Med. Internet Res. 2013, 15, e7.

22. Cader, R.; Campbell, S.; Watson, D. Judging nursing information on the www: A theoretical understanding. J. Adv. Nurs. 2009, 65, 1916-1925.

23. Kim, Y. Trust in health information websites: A systematic literature review on the antecedents of trust. Health Inform. J. 2016, 22, 355-369.

24. Klein, B. When do users detect information quality problems on the world wide web? In Proceedings of the Americas Conference on Information Systems (AMCIS), Dallas, TX, USA, 8 August 2002; p. 152.

25. Yang, H.; Thompson, C.; Bland, M. Do nurses reason 'adaptively'in time limited situations: The findings of a descriptive regression analysis. BMC Med. Inform. Decis. Mak. 2014, 14, 96.

26. Cummings, E.; Shin, E.H.; Mather, C.; Hovenga, E. Embedding nursing informatics education into an australian undergraduate nursing degree. Stud. Health Technol. Inform. 2016, 225, 329-333.

27. Scott, S.D.; Gilmour, J.; Fielden, J. Nursing students and internet health information. Nurse Educ. Today 2008, 28, 993-1001.

28. Arrigoni, C.; Vellone, E.; Alvaro, R.; Vanzetta, M.; Dal Molin, A. Social media and nurse education: An integrative review of the literature. J. Mass Commun. Journal. 2016, 6.

29. Solvoll, T.; Johnsen, E.; Bergmo, T.; Johansen, M. Evaluation of a Context Specific Communcation System Based on Smartphone. Nurses Use and Experiences. In Proceedings of the 14th Scandinavian Conference on Health Informatics 2016, Gothenburg, Sweden, 6-7 April 2016; Linköping University Electronic Press: Linköping, Sweden, 2016.; pp. 49-56.

30. Papastavrou, E.; Dimitriadou, M.; Tsangari, H.; Andreou, C. Nursing students' satisfaction of the clinical learning environment: A research study. BMC Nurs. 2016, 15, 44.

31. Pauleen, D.; Campbell, J.; Harmer, B.; Intezari, A. Making sense of mobile technology. Sage Open 2015, 5, 2.

32. Misko, J.; Beddie, F.; Smith, L. The recognition of non-formal and informal learning in Australia: Country background report prepared for the OECD activity on recognition of non-formal and informal learning. Commonwealth of Australia: Canberra, Australia, 2007. 
33. Morgan, R. Roy Morgan Image of Professions Survey 2016. Available online: http:/ /www.roymorgan.com/ findings/6797-image-of-professions-2016-201605110031 (accessed on 3 March 2017).

34. Shackleton-Jones, N. The importance of affective context: Push to pull learning. Glob. Focus Workplace Learn. $2012,6,17-20$.

(C) 2017 by the authors. Licensee MDPI, Basel, Switzerland. This article is an open access article distributed under the terms and conditions of the Creative Commons Attribution (CC BY) license (http://creativecommons.org/licenses/by/4.0/). 